\title{
Strut and tie model optimization for reinforced concrete bridge pier head structure using a genetic algorithm
}

\author{
Bambang Piscesa ${ }^{a^{*}}$, Tavio Tavio ${ }^{\mathrm{a}}$
}

\begin{abstract}
Strut and tie model (STM) is more suitable to design the pierhead structures which resist high shear forces transferred from the girders. These pierhead structures behave like the disturbed regions as in reinforced concrete deep beam. The design of the struts and ties elements requires the initial geometry configuration of the truss model where its boundaries are limited by the shape of the pier head structures. To find the optimum topological shape of the truss model, the genetic algorithm (GA) optimization technique is used in this paper. The objective functions in the GA optimization consisted of minimizing the usage of concrete and steel reinforcement material and ensuring all the stress ratios of the strut and tie elements are less than equal to unity. Both prestressed and non-prestressed pierheads are investigated in this paper. The use of prestressing in the pierhead structures reduces the stresses in the main tension tie significantly. Some shear tie and compression struts members also have almost zero stresses due to the presence of prestressing forces. For these elements with zero stresses, the elements can be removed and reduces the concrete and rebar materials usage. Furthermore, the genetic algorithm optimization is found to be successful to ensure all the stress ratio in the members to be less than equal to unity.
\end{abstract}

Keywords: Structural optimization, strut and tie model, genetic algorithm, reinforced concrete, pierhead

\section{INTRODUCTION}

The design of a double cantilever bridge pier head structure using the strut-and-tie model (STM) requires a well-known geometry of the structural truss system. To efficiently design the pierhead using the STM, trial-and-error of the truss structure model is required. This STM is based on the truss analogy for shear design firstly introduced by Ritter (1889) and Moersch (1902). Another important parameter when establishing the truss model is to ensure the angle between members falls into a certain range. Some researchers did propose the minimum angle between members. Schlaich and Weischede [1] suggested the value for the angle to be larger than 15 degrees. ACI 318-05 [2] noted that the angle should not be less than 25 degrees. Rogowsky et. al [3] and Ramirez and Breen [4] noted that the angle should be in the range of 25 to 65 degrees. Lastly, Grob and Thürlimann [5] proposed a range between 26.6 to 63.4 degrees for the angle between members.

In the author's previous work, a method for structural truss topology optimization using a genetic algorithm approach was proposed [6]. This genetic algorithm optimization can be categorized as the evolutionary approach which had been used widely in structural optimization. Some works in topological strut and tie model shapes optimization can be found in [7-13] [14].

In [6], the investigation was focused to optimize the height of a continuous deep beam member loaded with an asymmetric vertical load which would induce different forces in the member despite the symmetry of the truss system. Since the height of the continuous deep beam is constant, both the upper nodes can only move in the vertical direction. For the pierhead structures investigated in this paper, the top elevation is flat, but the bottom elevation can be adjusted based on the bending moment and shear capacities required. By noting that many girders can be placed at the top elevation of the bridge pier head, the movement of the truss nodes at the bottom part of the pierhead structures can be set to move differently during

${ }^{a}$ Lecturer in the Civil Engineering Department, Institut Teknologi Sepuluh Nopember, ITS Campus, Sukolilo, Surabaya 60111, Indonesia. Corresponding author email address: piscesa@ce.its.ac.id the topological optimization. Therefore, a more rational geometry shape of the pierhead structures can be obtained which are functions of the load in the girders and strength of the strut and tie members.

In this paper, the pier head structures modeled using STM are investigated to get the optimum topological shape of the structure. Both RC pierhead structures with and without prestressing reinforcement are considered in the investigation. The use of prestress in the RC pier head structure reduces the stresses in the main tension tie and can be reduced and can be used to further reduce the concrete and rear materials usage. However, to independently evaluate the performance of GA optimization for pierhead structures, the same amount of reinforcement in both the concrete compression strut and tie elements for both the prestressed and non-prestressed pie head structures are similar.

\section{RESEARCH SIGNIFICANCE}

This paper investigates the topological optimization of the double cantilever bridge pier head modeled with STM and is optimized using GA optimization. An in-house computer program is developed to support this research. There are two types of bridge pier head being investigated. One is without prestressing reinforcement and the other one had the prestressing reinforcement to reduce stresses in the main tension ties. The additional prestressing reinforcement is modeled as the external prestressing force in the STM structures.

\section{METHODOLOGY}

The research methodology consisted of constructing the geometry of the pier head structures, computing the applied load from the I-Girders, adding prestressing load for prestressed pier head structures, and optimizing the STM truss model using genetic algorithm optimization. STM design check based on ACI 318 is carried out for both the original and optimized STM truss topological shape. During the optimization, the assigned strut or tie element types do not change. In the GA optimization, the objective function is to reduce the concrete and steel reinforcement 
materials used with the constraint of design-strength-ratio (DSR) of the strut or tie element less than or equal to unity.

\section{A. GEOMETRY OF THE PIER HEAD STRUCTURE}

The initial geometry of the pierhead structure has a rectangular shape. The length of the pierhead is $11.5 \mathrm{~m}$. The thickness of the pierhead in the out-of-plane direction is $1.2 \mathrm{~m}$. The initial depth of the pierhead structure is 2.5 $\mathrm{m}$. The width of the column is $2.5 \mathrm{~m}$. The column height is $4.0 \mathrm{~m}$. Figure 1 shows the STM of the pierhead structure. The red nodes in Figure 1 showed the STM truss model which is used as an input geometry in the finite element analysis. The blue nodes in Figure 1 showed the boundary conditions or applied loads which is transferred to the red nodes during the analysis. The supports are in nodes 10 and 11 which are set to hinges. The applied loads from the girders are in nodes $1,3,5,7$, and 9 (five girders). In the case of prestressed pier head structures (straight tendon between node 10 and 11 was shown in Figure 1 as a black straight line), the applied prestressed loads are given in node 10 and 11 by applying the inward forces in both points. In the optimization process, only node $12,13,14$, $15,18,19,20$, and 21 can move in the vertical direction. All the allowed to move nodes are independent of each other.

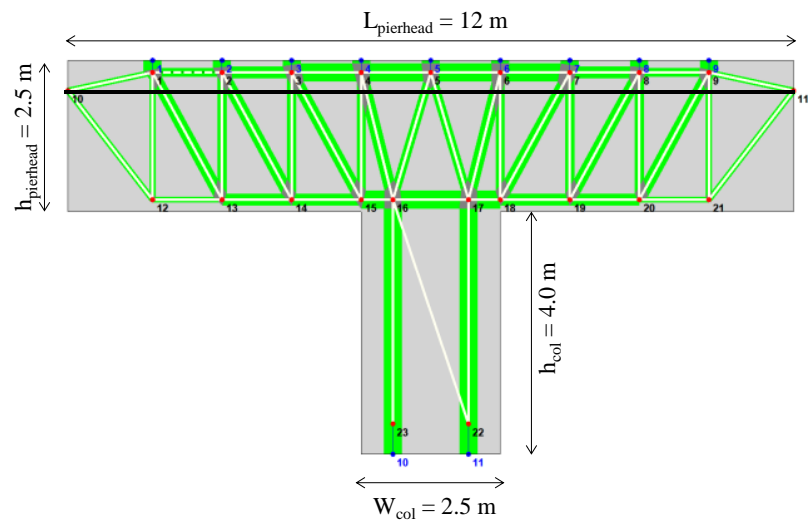

Figure 1 Initial model geometry of the pier head structure

\section{B. APPLIED LOADS AND BOUNDARY CONDITIONS}

The pier head structure has two symmetry cantilever beams supporting give prestressed I-Girders with a clear span of $30 \mathrm{~m}$. The center-to-center (c.t.c) distance between girders is $1.85 \mathrm{~m}$ and the girder height is $1.60 \mathrm{~m}$. The reaction from the girder is computed using the vehicle load based on SNI 1725-2016. By noting that the investigated bridge is a continuous span type, for each load point in the pier head, there exist two I-Girder loads. Therefore, the sum of the dead and live loads $\left(\mathrm{V}_{\mathrm{D}}\right.$ and $\left.\mathrm{V}_{\mathrm{L}}\right)$ for two I-Girder supported are $724 \mathrm{kN}$ and $522 \mathrm{kN}$, respectively. Applying the load factor for both the dead load and live load by 1.3 and 1.8 resulted in the ultimate load $\left(\mathrm{V}_{\mathrm{U}}=1.3 \mathrm{~V}_{\mathrm{D}}+1.8 \mathrm{~V}_{\mathrm{L}}\right)$ equal to $1880.8 \mathrm{kN}$.

Figure 2 shows the vertical load position $\left(\mathrm{V}_{\mathrm{U}}\right)$ from the girder and horizontal load position $\left(\mathrm{H}_{\mathrm{U}}\right)$ from prestressing forces. As previously discussed, the prestress forces are applied in the inward direction and are computed based on 70 percent capacity of 12 strands with $15.2 \mathrm{~mm}$ diameter and $140 \mathrm{~mm}^{2}$ nominal area. By noting that the ultimate strength of the strand is $1860 \mathrm{MPa}$, the prestress forces $\mathrm{H}_{U}$ can be computed as $1560 \times 140 \times 12 \times 0.7 / 1000=2187.36 \mathrm{kN}$.

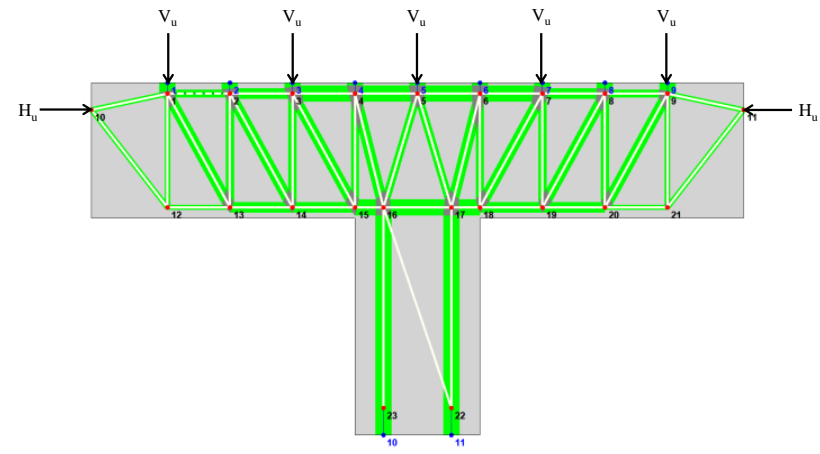

Figure 2 Applied ultimate vertical load from girder $\left(\mathrm{V}_{\mathrm{u}}\right)$ and horizontal prestressed load $\left(\mathrm{H}_{\mathrm{u}}\right)$

\section{STRUT AND TIE ELEMENT TYPES}

For the compression strut elements, there are two types of elements used. The element types are the ACI prismatic struts and ACI bottle-shaped strut with steel reinforcement. Since the concrete compressive strength used in this study is $30 \mathrm{MPa}$, the stress limit for ACI prismatic struts and ACI bottle-shaped struts are $19.13 \mathrm{MPa}$ and $14.33 \mathrm{MPa}$, respectively. The minimum widths used in the design check is 100, 200, and $300 \mathrm{~mm}$.

Table 1 Element connectivity table, strut and tie types, and width of the element

\begin{tabular}{|c|c|c|c|c|}
\hline ID & Node i & Node $\mathrm{j}$ & Strut and Tie Type & $\begin{array}{l}\text { Width } \\
(\mathrm{mm})\end{array}$ \\
\hline 1 & 1 & 2 & 3L-6D29-300 & 200 \\
\hline 2 & 2 & 3 & $3 \mathrm{~L}-6 \mathrm{D} 29-300$ & 200 \\
\hline 3 & 3 & 4 & 5L-7D29-300 & 300 \\
\hline 4 & 4 & 5 & $5 \mathrm{~L}-7 \mathrm{D} 29-300$ & 300 \\
\hline 5 & 5 & 6 & $5 \mathrm{~L}-7 \mathrm{D} 29-300$ & 300 \\
\hline 6 & 6 & 7 & 5L-7D29-300 & 300 \\
\hline 7 & 7 & 8 & $3 \mathrm{~L}-6 \mathrm{D} 29-300$ & 200 \\
\hline 8 & 8 & 9 & 3L-6D29-300 & 200 \\
\hline 9 & 10 & 1 & ACI Prismatic Struts & 100 \\
\hline 10 & 11 & 9 & ACI Prismatic Struts & 100 \\
\hline 11 & 10 & 12 & ACI Prismatic Struts & 100 \\
\hline 12 & 12 & 13 & ACI Prismatic Struts & 100 \\
\hline 13 & 13 & 14 & ACI Prismatic Struts & 200 \\
\hline 14 & 14 & 15 & ACI Prismatic Struts & 200 \\
\hline 15 & 15 & 16 & ACI Prismatic Struts & 300 \\
\hline 16 & 16 & 17 & ACI Prismatic Struts & 300 \\
\hline 17 & 17 & 18 & ACI Prismatic Struts & 300 \\
\hline 18 & 18 & 19 & ACI Prismatic Struts & 200 \\
\hline 19 & 19 & 20 & ACI Prismatic Struts & 200 \\
\hline 20 & 20 & 21 & ACI Prismatic Struts & 100 \\
\hline 21 & 21 & 11 & ACI Prismatic Struts & 100 \\
\hline 22 & 12 & 1 & 1L-8D19-100 & 100 \\
\hline 23 & 13 & 2 & 1L-8D19-100 & 100 \\
\hline 24 & 14 & 3 & 3L-8D19-200 & 200 \\
\hline 25 & 15 & 4 & 3L-8D19-200 & 200 \\
\hline 26 & 16 & 4 & ACI Bottle Shaped with Steel & 200 \\
\hline 27 & 16 & 5 & ACI Bottle Shaped with Steel & 150 \\
\hline 28 & 17 & 5 & ACI Bottle Shaped with Steel & 150 \\
\hline 29 & 17 & 6 & ACI Bottle Shaped with Steel & 200 \\
\hline 30 & 18 & 6 & 3L-8D19-200 & 200 \\
\hline 31 & 19 & 7 & $3 \mathrm{~L}-8 \mathrm{D} 19-200$ & 200 \\
\hline 32 & 20 & 8 & 1L-8D19-100 & 100 \\
\hline 33 & 21 & 9 & 1L-8D19-100 & 100 \\
\hline 34 & 1 & 13 & ACI Bottle Shaped with Steel & 200 \\
\hline 35 & 2 & 14 & ACI Bottle Shaped with Steel & 200 \\
\hline 36 & 3 & 15 & ACI Bottle Shaped with Steel & 200 \\
\hline 37 & 7 & 18 & ACI Bottle Shaped with Steel & 200 \\
\hline 38 & 8 & 19 & ACI Bottle Shaped with Steel & 200 \\
\hline 39 & 9 & 20 & ACI Bottle Shaped with Steel & 200 \\
\hline 40 & 16 & 23 & ACI Prismatic Struts & 300 \\
\hline 41 & 17 & 22 & ACI Prismatic Struts & 300 \\
\hline 42 & 16 & 22 & ACI Prismatic Struts & 1 \\
\hline
\end{tabular}

For the ACI prismatic struts, the efficiency factor is 0.85 , and the strength reduction factor is 0.75 . For the ACI 
bottle-shaped strut the efficiency factor 0.637 and the strength reduction factor is 0.75 . The details of the assigned width to the element ID are shown in Table 1.

For the main tie elements, there are two types of tie elements with different layers and rebar amount for each layer. To differentiate the types, identity notations are used here. There are 5L-7D29-300 and 3L-6D29-200. In the first term, the number showed the amount of the layer. In the second term, the amount of rebar for each layer and its diameter were shown. Please note that the D29 rebar has a nominal diameter of $28.7 \mathrm{~mm}$. In the last term, the number shows the width of the tie element. The minimum width of the main tension tie element was computed from the outer layer reinforcement plus $35.65 \mathrm{~mm}$ for rounding purposes. The distance between each layer is $50 \mathrm{~mm}$. For the tie elements that resist shear forces, there are two types of elements used. These elements are identified as 3L-8D19200 and 1L-8D19-100. The extension from the outer layer to determine the minimum tie width is $40.45 \mathrm{~mm}$. The explanation of the identity is similar to the main tie elements.

\section{GENETIC ALGORITHM PROPERTIES}

Table 2 shows the GA properties input data which consisted of the maximum GA iteration ( $\left.\mathrm{N}_{\mathrm{Max}}\right)$, population size $\left(\mathrm{P}_{\text {Size }}\right)$, chromosome length per variable $\left(\mathrm{Ch}_{\text {Length }}\right)$, crossover probability $\left(\mathrm{Cr}_{\mathrm{Prob}}\right)$, and mutation probability $\left(\mathrm{M}_{\mathrm{Prob}}\right)$. The total number of solving the linear system of equation $\{\mathrm{F}\}=[\mathrm{K}]\{\mathrm{u}\}$ in the finite element analysis is equal to $\mathrm{N}_{\text {Max }}$ times the $\mathrm{P}_{\text {Size }}$ which is about $2 \times 10^{5}$ times. For each linear system of equation, the stiffness matrix is different due to different topological condition of the STM truss shape. The precision of the variable is governed by the $\mathrm{Ch}_{\text {Length }}$ parameter which is equal to a 10-bit precision floating point. However, when solving the linear system of equation $\{\mathrm{F}\}=[\mathrm{K}]\{\mathrm{u}\}$ double-precision floating-point is used which is equal to 64-bit precision floating point. This indicates that the variable used as an input in the GA is based on binary input. The values for $\mathrm{Cr}_{\text {Prob }}$ and $\mathrm{M}_{\text {Prob }}$ are set to 0.8 and 0.01 respectively.

Table 2 Genetic algorithm properties input

\begin{tabular}{lc}
\hline Genetic Algorithm Properties & Value \\
\hline Maximum GA iteration & 1000 \\
Population size & 200 \\
Chromosom length per variable & 10 \\
Crossover probability & 0.8 \\
Mutation probability & 0.01 \\
\hline
\end{tabular}

\section{ANALYSIS AND DISCUSSIONS}

\section{A. STRUCTURAL ANALYSIS AND DESIGN CHECK OF THE INITIAL STM MODELS}

The structural analysis of the initial STM models is carried out using finite element analysis with two-dimensional truss elements. Once the axial forces in the elements are obtained, the strength of each strut and tie members are checked based on ACI 318-05. Figure 3 and Figure 4 show the analysis and design result of the initial STM models without and with prestressing reinforcement. In Figure, 3 notice that two vertical ties that carry shear forces in the pierhead are having their stress ratio (SR) greater than unity $(\mathrm{SR}=1.823)$. This means that in the strength design check, the member strength is not adequate to carry ultimate forces acting on the member. It is possible to add more reinforcing steel in these vertical ties or enlarge the effective width of diagonal bottle-shaped strut elements to reduce the SR below unity. However, the initial design results were not changed to evaluate whether the GA optimization can somehow find a solution that can reduce the SR of these overstressed members less than unity.

In addition to the tie's element, which is failing, there are two compression struts with bottle-shaped strut with reinforcement also failing under compression. The stress ratio for these diagonal compression struts is 1.127 and 1.247. On the other hand, the highest tensile forces were found at the top middle main tie elements. The tensile force acting on the element is $5059 \mathrm{kN}$ with the $\mathrm{SR}$ is 0.745 . The maximum compression forces were also found at the middle main strut elements with axial compression force equal to $5093 \mathrm{kN}$ and $\mathrm{SR}=0.74$. Since the applied loads are symmetrical, the axial force in the column compression strut is equal to $4702 \mathrm{kN}$. To check the validity of the analysis, the total internal force in the compression struts is $4702 \mathrm{kN}$ times two is equal to the applied load from the girder which is 1880.8 times five.

To gain an insight into the effect of prestressing forces on the pier head structure, an analysis and design check for the strut and tie elements was also carried out. The analysis result and strength design check of the members are shown in Figure 4. As shown in Figure 4, the vertical ties element which carries shear forces did not show any change in the internal forces and eventually gives similar SR to the previous model. The additional compression forces due to prestressing reduces the tensile force in the main top tie elements and increases the compression force in the main bottom strut elements. Since the tensile force at the main top tie elements reduces from $5093 \mathrm{kN}$ to $3185 \mathrm{kN}$, the stress ratio also drops from 0.740 to 0.469 . On the other hand, the axial compression force in the main bottom strut elements increases from $4780 \mathrm{kN}(\mathrm{SR}=0.694)$ to $5093 \mathrm{kN}$ $(\mathrm{SR}=0.740)$. Hence, it can be concluded that by adding prestressing force, the tensile force in the main top tie element reduces and therefore the used mild reinforcement can also be significantly reduced. Please note that this prestressing force also increases the axial compression force in the main bottom strut elements and thus it should be checked in the analysis whether the SR of the compression strut is still adequate to carry additional forces from prestressing reinforcement.

\section{B. GENETIC ALGORITHM OPTIMIZATION RESULTS}

Figure 5 and Figure 6 show the GA optimization results of the best topological shape that represents the most economical solution of the materials used and satisfying all the stress ratio in member to be less than unity. The location of the maximum stress ratio in the STM for pier head structures with and without prestressing are not identical. In the case of non-prestressed pier head structures, as shown in Figure 5, member 1-13 and 20-9 had their stress ratio equal to unity. There are four members (member 4-15, 4-16, 6-18, and 6-17) who had a very low axial force with a stress ratio below 0.006 . This means the member function is only for the stability of the truss model. This can be well understood as in points 4 and 7, there are no vertical loads given. If the vertical loads in points 4 and 


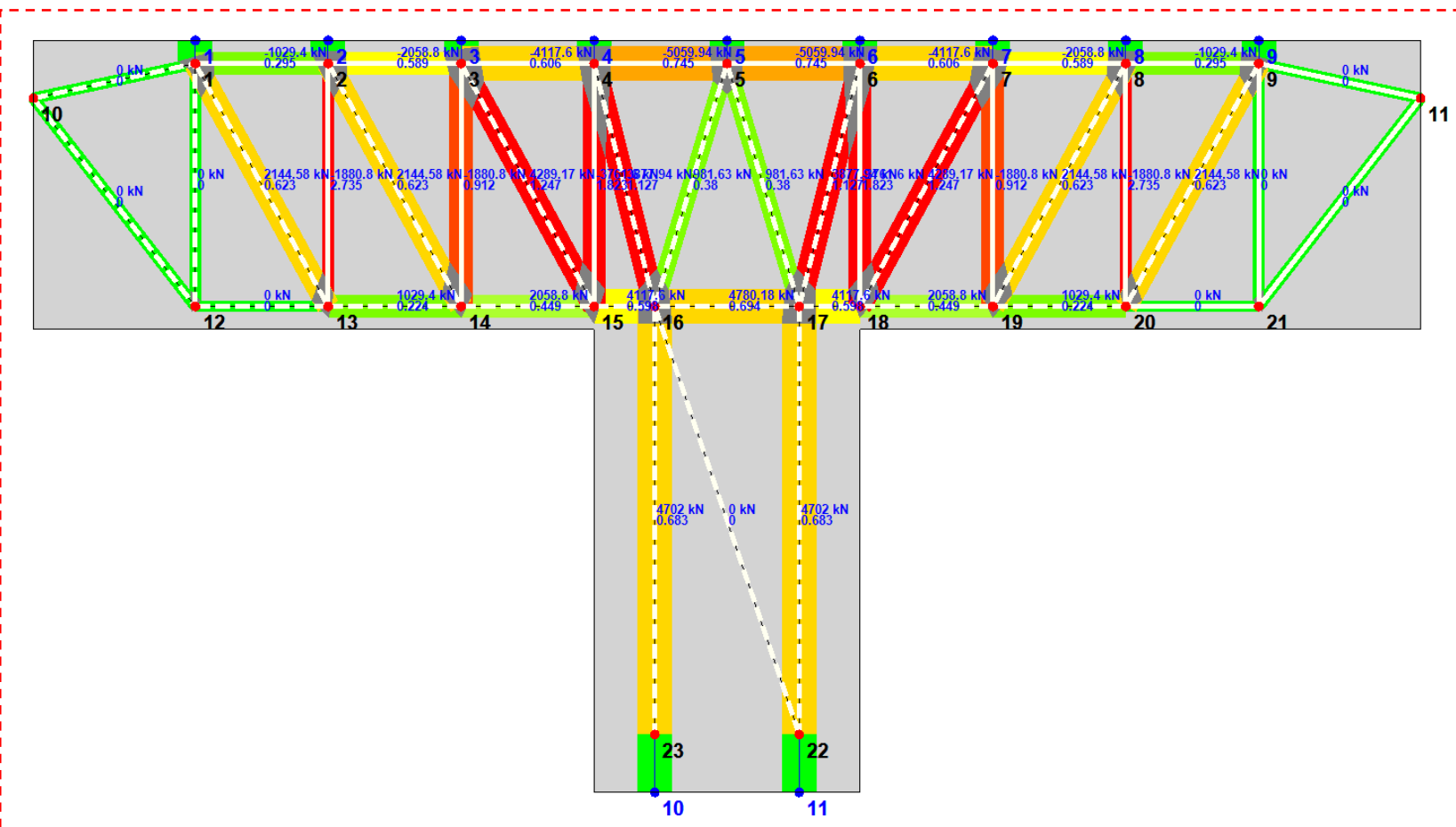

Figure 3 Analysis and design result of the STM without prestress reinforcement

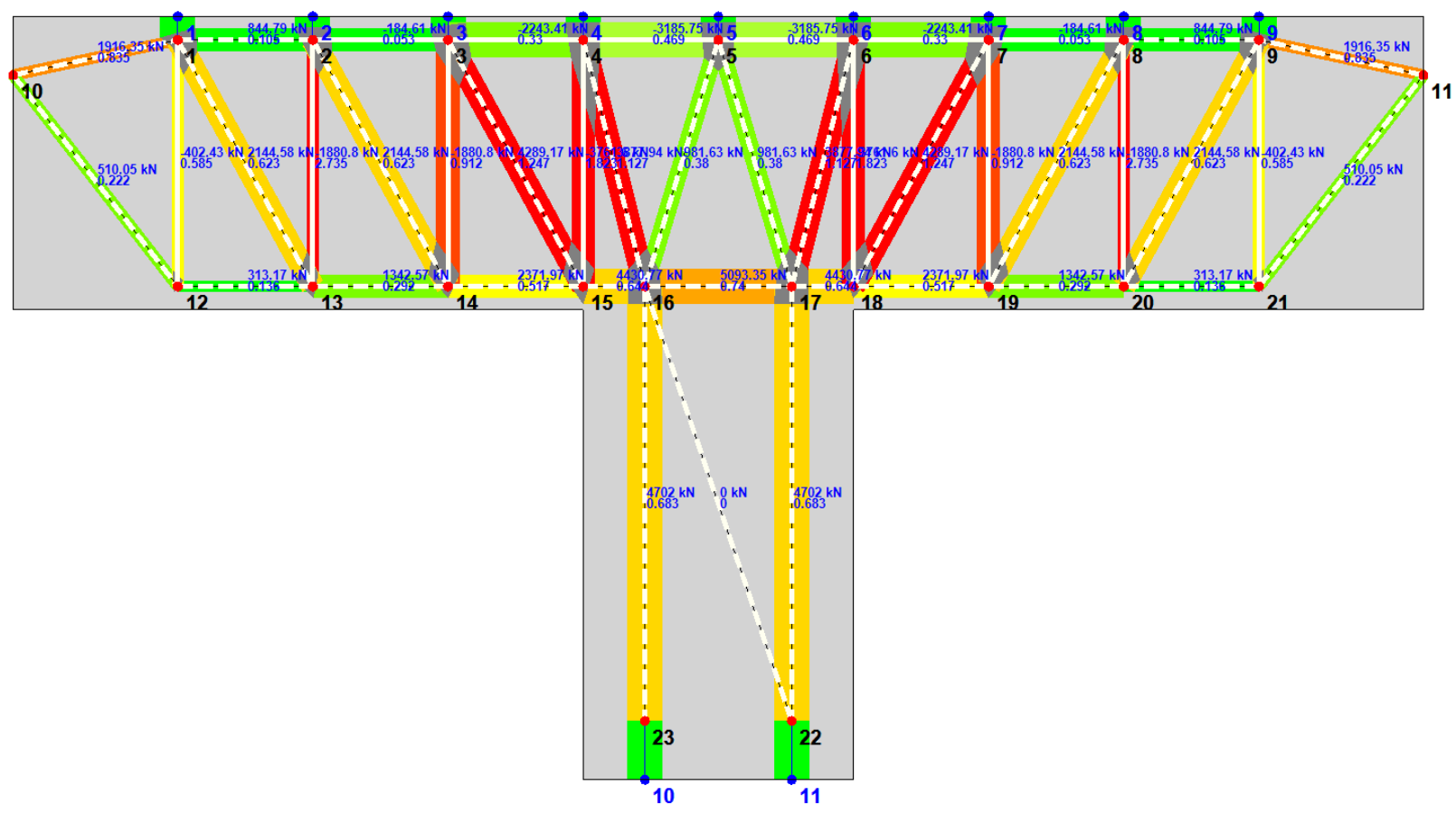

Figure 4 Analysis and design result of the STM with prestress reinforcement

7 have existed, the member's forces would not be close to zero.

On the other hand, the location of the maximum stress ratio for the prestressed pier head structures located on members $14-15$ and 18-19 with the stress ratio equal to 0.995 but still less than unity. In contrast with the nonprestressed pier head structure, the member which had almost zero axial forces are located on members 2-13, 2 $14,3-14,4-15,4-16,6-17,6-18,7-19,8-19$, and 8-20. The spread of these non-zero members is believed to be the result of applying prestressing forces. Furthermore, it did seem that the GA optimization tries to remove forces from the non-critical elements to the primary main truss members which carry the loads. It is possible to do element deletion for the almost zero elements to further improve the steel reinforcement material usage.

The utilization of the compressive strut for the nonprestressed pier head structure was found to be less than the prestress pier head structure. For the non-prestressed pier head structure, the stress ratio utilization for the main bottom compressive struts is $0,0.695,0.769$, and 0.915 for members $12-13,13-14,14-15$, and 15-16, respectively. In the prestressed pier head structure, the stress ratio utilization with the same member sequentially is 0.577 , 


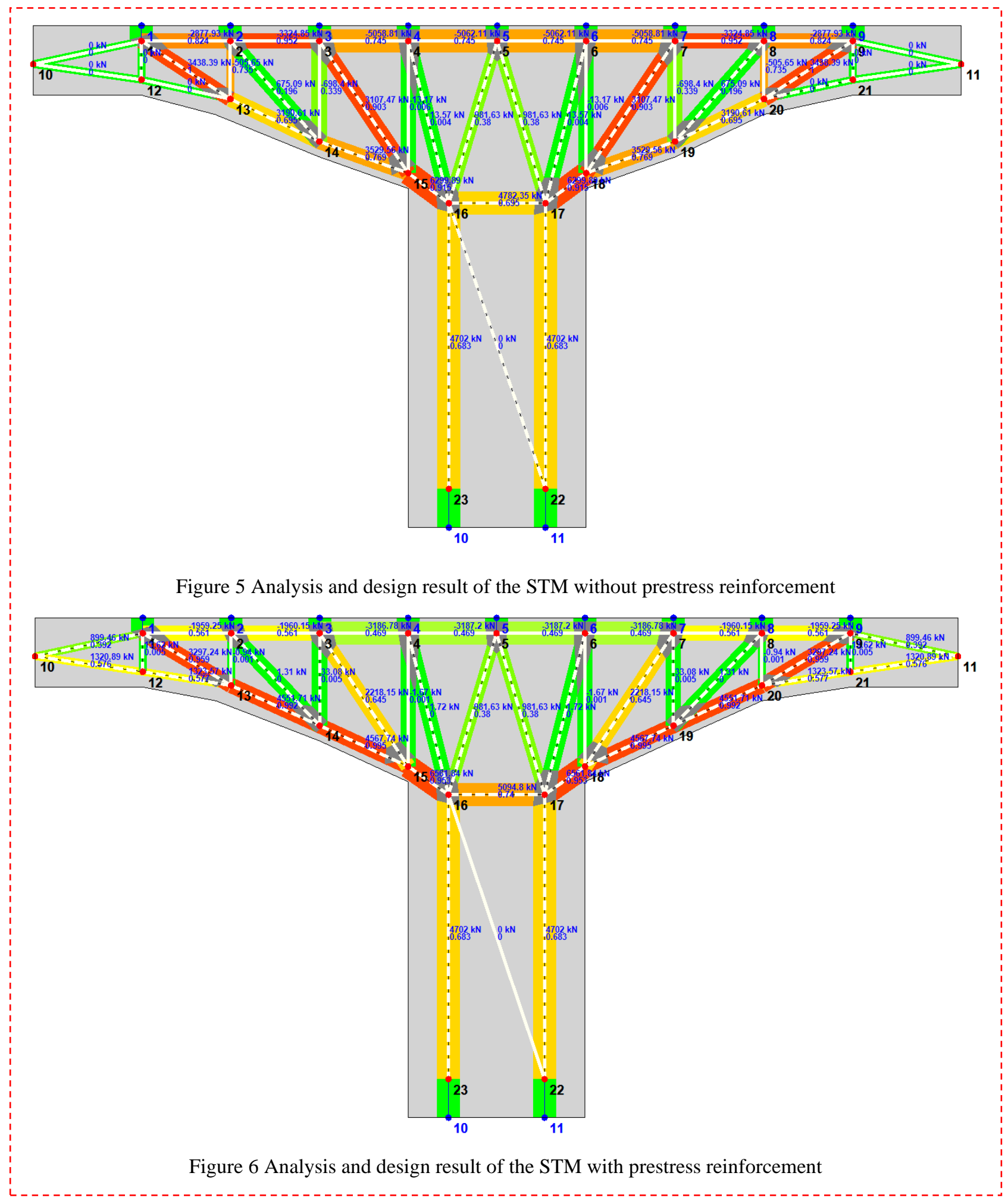

$0.992,0.995$, and 0.953. By having more forces stored in the compression struts, the forces in the main tie element will be reduced significantly and thus reduces the use of the main steel reinforcement which is quite expensive.

Since the prestressing force applied in the pier head structure reduces the tensile forces in the main tie elements, the stress ratio utilization for members 2-3 drops from 0.952 to 0.561 which is around a $41.07 \%$ reduction in forces and can also be applied to the reduced amount of steel reinforcement. It should be noted that the additional strand should also be included in the cost analysis, it was worth to be investigated as this prestressing strand has much higher steel yield strength than conventional mild steel reinforcement.

\section{CONCLUSIONS}

This paper has presented optimization of bridge pier head structure using genetic algorithm optimization. An inhouse computer program was developed for this purpose. The analysis of the member forces was based on finite element analysis of two-dimensional truss elements. There are two types of bridge pier head structure being optimized using GA. The first bridge pier head consisted of only reinforced concrete structures which are typically only 
concrete and mild steel reinforcement. In the second bridge pier head, additional prestressing reinforcement was added and was converted into prestressing force at the tendon anchorage point. The objective function in the GA optimization was to minimize the materials used for both the concrete and mild steel reinforcement while at the same time not allowing any stress ratio in the member greater than unity.

To evaluate the performance of the GA optimization, in the original STM, some members were intentionally designed to have their stress ratio be greater than unity. The purpose was to test whether the objective function used can be used to optimize the topological shape of the STM. From the GA optimization, it was found out that the used optimization algorithm was able to simultaneously minimize the usage of the material and ensuring the stress ratio of the members to be less than unity.

In the case of the optimized pierhead structures with prestressing reinforcement, it was obtained that some members had almost zero stresses which were convenient since there is no applied load given in the top node of the corresponding members. However, in the initial analysis, the mentioned members were stressed. This explains that the GA optimization tried to remove unnecessary forces in some unimportant members to the primary member that can effectively carry the forces. For these members that had almost zero stresses, a deletion algorithm can be added for a further tune-up in the computer code.

It should be noted that during the optimization process, there is no check on the minimum angle between the two trusses, the strength of the nodal zone is not included, and the member properties did not change during the process. This means that there are some rooms for the research to be improved in the future. By having the strength of the nodal zone being evaluated, it is possible to compute the width of the strut and tie elements during the runtime. This way, manual evaluation of the strut and tie elements width can be avoided. Moreover, with the features of selfadjusting member properties, it is possible to have more reduction in the usage of the material.

\section{REFERENCES}

[1] J. Schlaich and D. Weischede, "Detailing of concrete structures," Bulletin d'Information, vol. 150, p. 163, 1982.

[2] A. Committee, "Building code requirements for structural concrete (ACI 318-05) and commentary (ACI 318R-05)," 2005: American Concrete Institute.

[3] D. M. Rogowsky, J. G. MacGregor, and S. Y. Ong, "Tests of reinforced concrete deep beams," 1983.

[4] J. A. Ramirez and J. E. Breen, "Evaluation of a modified truss-model approach for beams in shear," Structural Journal, vol. 88, no. 5, pp. 562-572, 1991.

[5] J. Grob and B. Thürlimann, "Ultimate strength and design of reinforced concrete beams under bending and shear," in Ultimate Strength and Design of Reinforced Concrete Beams under Bending and Shear/Résistance et dimensionnement des poutres en béton armé soumises à la flexion et à l'effort tranchant/Bruchwiderstand und Bemessung von Stahlbetonbalken unter Biegung und Schub: Springer, 1976, pp. 107-120.
[6] B. Piscesa and T. Tavio, "Strut and tie model optimization for reinforced concrete deep beam using genetic algorithm," Journal of Civil Engineering, vol. 35, no. 1, pp. 14-18, 2020.

[7] R. Perera and J. Vique, "Strut-and-tie modelling of reinforced concrete beams using genetic algorithms optimization," Construction and Building Materials, vol. 23, no. 8, pp. 2914-2925, 2009.

[8] R. Perera, J. Vique, A. Arteaga, and A. De Diego, "Shear capacity of reinforced concrete members strengthened in shear with FRP by using strut-and-tie models and genetic algorithms," Composites Part B: Engineering, vol. 40, no. 8, pp. 714-726, 2009.

[9] X. Liu, W.-j. Yi, and P.-s. Shen, "Topology optimization of strut-and-tie models in deep reinforced concrete beams," Engineering Mechanics, vol. 9, 2006.

[10]F. Bontempi and P. G. Malerba, "Stress path adapting strut-and-tie models in cracked and uncracked RC elements," Structural Engineering and Mechanics, vol. 12, no. 6, pp. 685-698, 2001.

[11] A. N. Hanoon, M. Jaafar, F. Hejazi, and F. N. A. Aziz, "Strut-and-tie model for externally bonded CFRPstrengthened reinforced concrete deep beams based on particle swarm optimization algorithm: CFRP debonding and rupture," Construction and Building Materials, vol. 147, pp. 428-447, 2017.

[12] J. L. Jewett and J. V. Carstensen, "Experimental investigation of strut-and-tie layouts in deep RC beams designed with hybrid bi-linear topology optimization," Engineering Structures, vol. 197, p. 109322, 2019.

[13] Q. Q. Liang, Y. M. Xie, and G. P. Steven, "Topology optimization of strut-and-tie models in reinforced concrete structures using an evolutionary procedure," American Concrete Institute, 2000.

[14] Q. Q. Liang, B. Uy, and G. P. Steven, "Performancebased optimization for strut-tie modeling of structural concrete," Journal of Structural Engineering, vol. 128, no. 6, pp. 815-823, 2002. 